\title{
Secreted Frizzled Related Protein 2 Modulates Epithelial-Mesenchymal Transition and Stemness via Wnt/ $\beta$-Catenin Signaling in Choriocarcinoma
}

\author{
Xianling Zeng ${ }^{a}$ Yafei Zhang ${ }^{b}$ Huiqiu Xua Taohong Zhang ${ }^{a} \quad$ Yan Xue $^{a}$ \\ Ruifang $\mathrm{An}^{\mathrm{a}}$ \\ aDepartment of Obstetrics and Gynecology, The First Affiliated Hospital of Xi'an Jiaotong University, \\ Xi'an, ${ }^{b}$ Department of General Surgery, The Second Affiliated Hospital of Xi'an Jiaotong University, \\ Xi'an, China
}

\section{Key Words}

Secreted frizzled related protein 2 - Epithelial-mesenchymal transition - Stemness $-\mathrm{Wnt} / \beta$ catenin • Choriocarcinoma

\begin{abstract}
Background/Aims: Choriocarcinoma (CC) is a highly aggressive gestational trophoblastic neoplasia; however, the underlying molecular mechanisms of its invasiveness and metastasis remain poorly understood. Human secreted frizzled-related protein 2 (SFRP2) could function as a tumor promoter or suppressor in different tumors, yet the role it plays in CC's invasion and metastasis is thoroughly unclear. The current study was aimed to explore the function and underlying mechanism of SFRP2 in CC. Methods: The expression of SFRP2 in CC tissues was examined via immunohistochemistry. The methylation level and expression of SFRP2 in CC cell lines, JEG-3 and JAR were examined via bisulfite sequencing PCR (BSP), western blotting and quantitative RT-PCR. The biological role of increasing expressed SFRP2 through its promoter demethylation with 5-Aza-2'-deoxycytidine (5-Aza) was examined by a series of in vitro functional studies. Furthermore, lentivirus transfection technology was adopted to investigate the biological roles of SFRP2 knockdown in JEG-3 and JAR cells in vitro and in vivo. Moreover, its downstream signaling pathway was investigated. Results: SFRP2 was downregulated in CC tissues, and its expression was inversely related to its promoter hypermethylation frequency in JEG-3 and JAR cells. Increased SFRP2 through its promoter demethylation inhibited cell migration, invasion and colony formation in JEG-3 and JAR cells, whereas decreased SFRP2 reversed the epithelial-mesenchymal transition (EMT) process and stemness in JEG-3 and JAR cells both in vitro and vivo. Mechanistically, SFRP2 regulated the EMT and stemness of CC cell lines via canonical Wnt/ $\beta$-catenin signaling, validated by the usage of a Wnt activator
\end{abstract}




\section{Cellular Physiology Cell Physiol Biochem 2018;50:1815-1831 \\ \begin{tabular}{l|l|l} 
and Biochemistry & Dublished online: 3 November 2018 & $\begin{array}{l}\text { (c) } 2018 \text { The Author(s). Published by S. Karger AG, Basel } \\
\text { www.karger.com/cpb }\end{array}$
\end{tabular} \\ Zeng et al.: Secreted Frizzled Related Protein 2 Modulates Epithelial-Mesenchymal}

Transition and Stemness

and inhibitor. Conclusion: The current study indicates that downregulated SFRP2 has potent tumor-promotive effects in CC through the modulation of cancer stemness and the EMT phenotype via activation of Wnt/ $\beta$-catenin signaling in vitro and in vivo.

(C) 2018 The Author(s)

Published by S. Karger AG, Basel

\section{Introduction}

Choriocarcinoma (CC) is a highly aggressive gestational trophoblastic neoplasia (GTN), which primarily occurs among women of reproductive ages. It originates from abnormal trophoblastic hyperplasia; it may be secondary to various types of pregnancies and frequently follows hydatidiform molar (HM), abortion, ectopic pregnancies and pre-term or term labor [1]. The incidence of CC has been estimated to be 1:40, 000-50, 000 pregnancies and 1:40 HM cases [2]. Moreover, $\mathrm{CC}$ is extremely prone to invade the uterus and surrounding organs, and it is common to have distant metastasis, particularly to the lung; however, it may also involve the liver, spleen, kidneys, bowels, and brain [3]. Although the overall survival rate of lowrisk CC is approximately $100 \%$, in high-risk metastatic CC, it is difficult to achieve complete remission and often leads to a high mortality, threatening women's quality of life and causing a substantial economic burden [4]. Thus, it is imperative to explore the underlying molecular mechanisms of its invasiveness and early metastasis and further provide novel therapeutic targets to improve patient prognosis.

Wnt/ $\beta$-catenin signaling is highly conserved and plays an essential role in various biological processes during embryonic differentiation, placentation and tumorigenesis. Accumulating studies have indicated that Wnt signaling plays an indispensable role in the development of various cancers [5-8]. The Wnt/ $\beta$-catenin pathway is in the "off" state when no Wnt ligand binds to the Frizzled/low density lipoprotein receptor related protein (LRP) receptor complex. Cytoplasmic $\beta$-catenin is subsequently recruited to the destruction complex (DC), which consists of adenomatous polyposis coli (APC), Axin, and glycogen synthase kinase-3 $\beta$ (GSK-3 $\beta$ ), thus resulting in the phosphorylation of $\beta$-catenin by the phosphorylation of GSK-3 $\beta$ (p-GSK-3 $\beta$ ) and subsequent degradation via the ubiquitin proteosome pathway. In contrast, when Wnt ligand binds to Frizzled/ LRP receptor complex, the Wnt/ $\beta$-catenin pathway is in the "on" state, and disheveled 3 (Dvl3) simultaneously starts to accumulate, thereby preventing the formation of DC, which results in the inhibition of GSK-3 $\beta$ activity, leads to the unphosphorylation of $\beta$-catenin and eventually results in the suppression of $\beta$-catenin degradation. The increased accumulation of cytoplasmic $\beta$-catenin subsequently translates into the nucleus, interacting with related transcription factors to activate the target genes [9].

Human secreted frizzled-related proteins (SFRPs) constitute a family of five conserved proteins (SFRP1, 2, 3, 4 and 5) that have broad implications in embryonic development and pathological conditions, including tumorigenesis. SFRP2 is an antagonist of the Wnt/ $\beta$ catenin pathway in view that it has a cysteine rich domain (CRD) homologous to the Frizzled CRD; thus, it could inhibit the activation of the Wnt/ $\beta$-catenin pathway. Numerous studies have reported that SFRPs could deregulate Wnt/ $\beta$-catenin signaling in tumors. However, Kaur et al. showed that SFRP2 in the aged microenvironment could drive melanoma metastasis [10]. Thus, its tumor-suppressive or carcinogenetic roles in cancer development remain controversial, and the role SFRP2 plays in CC's invasion and metastasis is thoroughly unclear.

The epithelial mesenchymal transition (EMT) plays a curial role in cancer invasion, metastasis and progression [11]. Approximately $90 \%$ of all cancer-related deaths are reported to be associated with tumor metastasis $[12,13]$. Previous evidence has also supported the EMT in the development of CC [14]. Moreover, cancer stem cells (CSC) have the capacity for self-renewal and a multipotent differentiation potential. They have been identified in many cancers, including colon cancer, leukemia, and breast cancer, and contribute to tumor growth, metastasis, and recurrence [15-17]. Interestingly, accumulating evidence has indicated a critical role for Wnt/ $\beta$-catenin signaling in CSCs [18-21]. However, the effect that the Wnt/ $\beta$ catenin signaling pathway exerts on EMT phenotypes and stemness remains unknown in CC. 


\section{Cellular Physiology Cell Physiol Biochem 2018;50:1815-1831 and Biochemistry \begin{tabular}{l|l} 
DOI: 10.1159/000494862 2018 The Author(s). Published by S. Karger AG, Basel \\
(c) 2018
\end{tabular}

Zeng et al.: Secreted Frizzled Related Protein 2 Modulates Epithelial-Mesenchymal

Transition and Stemness

Therefore, in this study, we will investigate the expression level of SFRP2 in CC specimens and CC cell lines, JEG-3 and JAR. Furthermore, we will determine the function of SFRP2 in CC and explore its role in EMT phenotypes and the stemness of CC.

\section{Materials and Methods}

\section{Cell culture and reagents}

The human first trimester extravillous trophoblast cell line (HTR-8) cultured in RPMI-1640 medium and human embryonic kidney 293T cells, as well as two human CC cell lines (JAR and JEG-3) cultured in DMEM medium supplemented with $10 \%$ fetal bovine serum and incubated in a $37^{\circ} \mathrm{C}$ humidified incubator that contained 5\% CO2, were obtained from the American Type Culture Collection (Manassas, VA, USA). 5-Aza-2'-deoxycytidine (5-Aza; ab120842, Abcam, Cambridge, UK) was added to the culture medium to induce demethylation in JAR and JEG-3 cells; XAV 939 (S1180, Selleckchem, Houston, TX) was added to the culture medium as a Wnt/ $\beta$-catenin pathway inhibitor at a final concentration of $2 \mu \mathrm{M}$. BML-284 (sc222416, Santa Cru, USA) was added to the culture medium as a Wnt/ $\beta$-catenin pathway activator at a final concentration of $5 \mu \mathrm{M}$. For the control cells, an equal dose of dimethylsulfoxide (DMSO) was added to the medium.

\section{Real-time reverse transcription polymerase chain reaction ( $q R T-P C R$ )}

Total cellular RNA was extracted using RNAfast 200 reagents (Fastagen Biotechnology, Shanghai, China) and was quantified by absorbance at $260 \mathrm{~nm}$. The RNA $(2 \mu \mathrm{g})$ sample was reversely transcribed with PrimeScript RT Master Mix, and quantitative PCR was performed with SYBR-Green PCR Master Mix (Takara Bio, Dalian, China). The gene-specific primer sequences are shown in Table 1. GAPDH was used as the internal control. The threshold cycle (Ct) value for triplicate reactions was averaged. The melting curve for the primers was analyzed to confirm the specificity of the PCR products. The relative expression of mRNA for each target gene was calculated as follows: $\Delta \mathrm{Ct}=\mathrm{Ct}$ (target) - Ct (GAPDH), $\Delta \Delta \mathrm{Ct}=\Delta \mathrm{Ct}-\Delta \mathrm{Ct}$ (calibrator), and the fold changes in mRNAs were calculated through relative quantification $\left(2^{-\Delta \Delta c t}\right)$.

\section{Western blotting}

Cells were washed three times with cold PBS and lysated in RIPA buffer (50 mM Tris pH 8.0, $150 \mathrm{mM} \mathrm{NaCl}$, $0.1 \%$ SDS, $1 \%$ NP- 40 , and $0.5 \%$ sodium deoxycholate) protease inhibitors $(1 \%$ inhibitor cocktail and $1 \mathrm{mM}$ PMSF) (Sigma) on ice. Approximately $20 \mu \mathrm{g}$ of protein were separated with 10$12 \%$ SDS-PAGE gel, transferred onto nitrocellulose membranes, and blocked with $5 \%$ non-fat dry milk in TBST at room temperature for $1 \mathrm{~h}$. The membrane was subsequently incubated with primary antibody with different dilutions by $5 \%$ BSA at $4{ }^{\circ} \mathrm{C}$ overnight, followed by a TBST wash and 1-h incubation with HRPconjugated secondary antibodies (Licor, Rockford, IL, USA) at room temperature. The membranes were scanned using a Molecular Imager ChemiDoc XRS System (Bio-Rad Laboratories, Hercules, CA, USA). The antibodies used are shown in Table 2. Loading differences were normalized using $\beta$-actin.
Table 1. Primers used for qRT-PCR

\begin{tabular}{|c|c|c|c|}
\hline Gene & Primers (sense/antisense $5^{\prime}-3^{\prime}$ ) & Product length (bp) & $\operatorname{Tm}\left({ }^{\circ} \mathrm{C}\right)$ \\
\hline SFRP1 & $\begin{array}{c}\text { TCCCTGTGACAACGAG } \\
\text { GTCCTTCTTCTTGATGGGC }\end{array}$ & 207 & 60 \\
\hline SFRP2 & $\begin{array}{l}\text { GGAGACCAAGAGCAAGACCAT } \\
\text { GCACTGCAAGCTGTCTTTGA }\end{array}$ & 228 & 60 \\
\hline SFRP3 & $\begin{array}{l}\text { TCGAGCAGTTCGAAGGTCTG } \\
\text { CACGAGTGGCGGTACTTGAT }\end{array}$ & 184 & 60 \\
\hline SFRP4 & $\begin{array}{l}\text { CACATCCTGCCCCATCAAGA } \\
\text { TCCTGAACTGTTCTCCGCTG }\end{array}$ & 161 & 59 \\
\hline SFRP5 & $\begin{array}{l}\text { CAGATGTGCTCCAGTGACTTTG } \\
\text { AGAAGAAAGGGTAGTAGAGGGAG }\end{array}$ & 184 & 60 \\
\hline$\beta$-catenin & $\begin{array}{l}\text { TTCGCCTTCACTATGGACTACC } \\
\text { GCACGAACAAGCAACTGAACTA }\end{array}$ & 175 & 59 \\
\hline Dvl3 & $\begin{array}{l}\text { TGGACGACGATTTCGGAGTG } \\
\text { TTATCAGCACAGAAGGGGGC }\end{array}$ & 139 & 60 \\
\hline Twist & $\begin{array}{l}\text { CGCCCCATGATATGGGTAGC } \\
\text { CCATGACTCGCTGGTTCTGA }\end{array}$ & 174 & 60 \\
\hline E-cadherin & $\begin{array}{l}\text { GGGCTCAAGTGACTCGTAACGA } \\
\text { CAGCCGCTTTCAGATTTTCATC }\end{array}$ & 202 & 59.9 \\
\hline $\mathrm{N}$-cadherin & $\begin{array}{l}\text { ACTTGCCAGAAAACTCCAGGG } \\
\text { CCCTAAATGAAACCGGGCATT }\end{array}$ & 209 & 60 \\
\hline Vimentin & $\begin{array}{l}\text { AGCTCTGCGTGAAGTTCGAT } \\
\text { TGCCTGGACTTGTCTACGTG }\end{array}$ & 175 & 59 \\
\hline MMP2 & $\begin{array}{l}\text { CACATCTGGGCAGTTGCTAA } \\
\text { TCTGGGGCAGTCCAAAGAAC }\end{array}$ & 144 & 59 \\
\hline MMP9 & $\begin{array}{l}\text { TTCCAAACCTTTGAGGGCGA } \\
\text { CTGTACACGCGAGTGAAGGT }\end{array}$ & 164 & 60 \\
\hline GAPDH & $\begin{array}{c}\text { AAATCAAGTGGGGCGATGCT } \\
\text { AGCCAAATTCGTTGTCATACTTCT }\end{array}$ & 186 & 59 \\
\hline
\end{tabular}




\section{Cellular Physiology Cell Physiol Biochem 2018;50:1815-1831 and Biochemistry \begin{tabular}{l|l} 
DOI: $10.1159 / 000494862$ & 2018 The Author(s). Published by S. Karger AG, Basel
\end{tabular}

Zeng et al.: Secreted Frizzled Related Protein 2 Modulates Epithelial-Mesenchymal

Transition and Stemness

Table 2. Primary antibodies used for western blotting

\begin{tabular}{|c|c|c|c|c|c|}
\hline Antibody & Catalog no. & Immunogen species & Source & Dilution & Molecular weight \\
\hline SFRP2 polyclonal & ab86379 & rabbit & Abcam, Cambridge, UK & $1.5 \mu \mathrm{g} / \mathrm{ml}$ & $33 \mathrm{kDa}$ \\
\hline$\beta$-catenin monoclonal & ab32572 & rabbit & Abcam, Cambridge, UK & $1: 5000$ & $92 \mathrm{kDa}$ \\
\hline GSK-3 $\beta$ monoclonal & ab32391 & rabbit & Abcam, Cambridge, UK & $1: 5000$ & $46 \mathrm{kDa}$ \\
\hline p-GSK-3 $\beta$ monoclonal & ab75814 & rabbit & Abcam, Cambridge, UK & $1: 5000$ & $47 \mathrm{kDa}$ \\
\hline Dvl3 monoclonal & ab76081 & rabbit & Abcam, Cambridge, UK & $1: 500$ & $78 \mathrm{kDa}$ \\
\hline Twist polyclonal & ab50581 & rabbit & Abcam, Cambridge, UK & $0.5 \mu \mathrm{g} / \mathrm{ml}$ & $26 \mathrm{kDa}$ \\
\hline E-cadherin monoclonal & ab76055 & mouse & Abcam, Cambridge, UK & $1: 500$ & $100 \mathrm{kDa}$ \\
\hline $\mathrm{N}$-cadherin polyclonal & ab18203 & rabbit & Abcam, Cambridge, UK & $1.0 \mu \mathrm{g} / \mathrm{ml}$ & $120 \mathrm{kDa}$ \\
\hline Vimentin monoclonal & ab92547 & rabbit & Abcam, Cambridge, UK & $1: 2000$ & $54 \mathrm{kDa}$ \\
\hline MMP2 polyclonal & ab37150 & rabbit & Abcam, Cambridge, UK & $1.0 \mu \mathrm{g} / \mathrm{ml}$ & $72 \mathrm{kDa}$ \\
\hline MMP9 polyclonal & ab38898 & rabbit & Abcam, Cambridge, UK & $1: 800$ & $92 \mathrm{kDa}$ \\
\hline Oct4 polyclonal & ab18976 & rabbit & Abcam, Cambridge, UK & $2 \mu \mathrm{g} / \mathrm{ml}$ & $45 \mathrm{kDa}$ \\
\hline Nanog monoclonal & ab62734 & mouse & Abcam, Cambridge, UK & $4 \mu \mathrm{g} / \mathrm{ml}$ & $35 \mathrm{kDa}$ \\
\hline$\beta$-actin monoclonal & sc-47778 & mouse & Santa Cru, USA & $1: 500$ & $43 \mathrm{kDa}$ \\
\hline
\end{tabular}

\section{MTT assay}

The tumor cell viability in the presence of increasing 5-Aza concentrations in two CC cell lines was measured by a 3- (4, 5-dimethylthiazol-2-yl)-2, 5-diphenyltetrazolium bromide (MTT) (Sigma, St. Louis, MO, USA) assay. The absorbance was measured at $490 \mathrm{~nm}$ using a universal microplate reader (Model ELx800; BioTek Instruments, Inc., Winooski, VT, USA). The 5-Aza concentrations ranged from $0 \mu \mathrm{M}$ in the DMSO control to $20 \mu \mathrm{M}$, whereas the incubation period was $24 \mathrm{~h}, 48 \mathrm{~h}$ and $72 \mathrm{~h}$. The viability of the treated cells was reported relative to the DMSO control.

\section{Bisulfite sequencing PCR (BSP)}

Genomic DNA samples were obtained from HTR-8, and JEG-3 and JAR were purified using DNAzol (Invitrogen). Bisulfite treatment of $2.0 \mu \mathrm{g}$ genomic DNA of placental tissues and trophoblast-like cell lines was performed using the EpiTect Bisulfite Kit (Qiagen, Hilden, Germany) according to the manufacturer's instructions. The base SFRP2 sequence was as follows: GATTGTATACGACTCACTATAGGGCGAATTGGGCCCGACGTCGCATGCTCCCGGCCGCCATGGCGGCCGCGGGAATT CGATTGGTAATTTAGTAGAAATTTCGGATTGGGGTAAAATAAGTTTGGGTTTTGGTGGTATGTGGGGTTAGGTGCG TTTTCGTTAGTATTTGGTCGCGAGGCCGTTCGCGGGGTGTTTTGTGTGTTTTTTATTCTTGTAGTTTGTGTTTTGTT TGTTTATTGTGGGGGTGTAGTGGTTAGGTTTTTTTGTTTGTTGTTTAAAGAAATTTTA.

The primers for bisulfite-converted DNA were SFRP2-F: 5'-GGTAATTTAGTAGAAATTTCGG-3' and MEST-R: 5'-TACGTTAAAAATACCCCTCAC-3'. Amplified bisulfate PCR products were subcloned into the TA vector system (Promega Corp., Madison, WI, USA) according to the manufacturer's instructions. Five clones were randomly selected for specific regions of the gene and were sent to Sangon Biotech (Shanghai, China) for sequencing.

\section{Enzyme-linked immunosorbent assay}

To measure the SFRP2 concentration in cultural supernatants, a sandwich enzyme-linked immunosorbent assay (ELISA) was performed using an SFRP2 ELISA kit (F00857, Xitang biotechnology, Shanghai, China) according to its protocol.

\section{Plasmid construction and lentiviral infection}

The plasmids were constructed according to standard methods. All structures were verified by appropriate restriction digestion and/or sequencing. The sequences of SFRP2 short hairpin RNAs (shRNAs) were as follows: shSFRP2-1: 5'- GATCCGCCACCCGAATCTTGTAGAAATTCAAGAGATTTCTACAAGATTCGGGT GGTTTTTTGG-3', shSFRP2-2: 5'- GATCCGGAAGCTCCAAAGGTATGTGAATCAAGAGTTCACATACCTTTGGAG CTTCTTTTTTGG-3'. The shRNAs were subsequently transfected with X-tremeGENE HP DNA transfection reagents (Roche Diagnostics, Indianapolis, IN, USA) into the pLKO.1 lentiviral vector (Addgene) following the manufacturer's instructions. For lentiviral infection, JEG-3 and JAR cells were plated overnight and subsequently infected with lentivirus in the presence of polybrene $(8 \mu \mathrm{g} / \mathrm{ml}$, Sigma-Aldrich). Lentivirus 


\section{Cellular Physiology Cell Physiol Biochem 2018;50:1815-1831 \begin{tabular}{l|l|l} 
and Biochemistry Published online: 3 November 2018 & $\begin{array}{l}\text { C } 2018 \text { The Author(s). Published by S. Karger AG, Basel } \\
\text { www.karger.com/cpb }\end{array}$
\end{tabular}}

Zeng et al:: Secreted Frizzled Related Protein 2 Modulates Epithelial-Mesenchymal

Transition and Stemness

empty vector that only expressed the green fluorescent protein (GFP) gene (JEG-3/JAR-vector) was used as a transfection control. Forty-eight hours after infection, the GFP expression was assessed to evaluate the infection efficiency, and the expression level of SFRP2 was examined by qRT-PCR and western blotting. The infected cells were selected with $1.5 \mu \mathrm{g} / \mathrm{ml}$ puromycin to establish the stable clone cell lines.

\section{Transwell assay}

Cell migration and invasion were performed via a Boyden chamber assay (Millipore, Chaffhausen, Switzerland). For invasion, the upper chamber of an 8-mm pore size coated with $60 \mu \mathrm{l}$ Matrigel (Sigma, St. Louis, MO, USA) was incubated in $37^{\circ} \mathrm{C}$ with $5 \% \mathrm{CO} 2$ for $4 \mathrm{~h}$. Then, $8 \times 10^{4}$ cells were seeded in the upper chamber in $200 \mu \mathrm{l}$ serum-free DMEM medium, and $800 \mu \mathrm{l}$ DMEM medium with $20 \%$ serum were added in the lower chamber of a 24-well plate. After $24 \mathrm{~h}$, the chambers were washed with PBS (pH 7.4) three times, fixed with $4 \%$ formalin for $10 \mathrm{~min}$, and stained with crystal violet ( $0.01 \%$ in ethanol, Sigma) for $20 \mathrm{~min}$. Five random fields were assessed under the inverted microscope at $\times 20$ magnification, and the cell number was counted. For the migration assay, $4 \times 10^{4}$ cells were directly seeded in the upper chamber without Matrigel, and the rest of the protocol was conducted in the same manner as the invision assay. The relative invasion or migration ability was expressed as a ratio of the control cells.

\section{Scratch wound assay}

JEG-3 and JAR cells after lentiviral transfection (shSFRP2 and vector) were scratched in 6-well plates with a pipette tip when the cells were at $80 \%$ confluence. Serum-free medium was subsequently added to the plates, and the width of the scratches was measured at $0 \mathrm{~h}, 24 \mathrm{~h}$, and $48 \mathrm{~h}$ after scratching.

\section{Immunofluorescence microscopy}

For immunofluorescence (IF) staining, approximately $8 \times 10^{3}$ cells were spotted on poly-D-lysinecoated slides (Thermo Fisher), fixed in $4 \%$ paraformaldehyde for $15 \mathrm{~min}$, permeabilized with $0.1 \%$ Triton $\mathrm{X}-100$ for $15 \mathrm{~min}$ and blocked in 5\% BSA for $30 \mathrm{~min}$. The cells were subsequently incubated with primary antibody ( $\beta$-catenin, 1:100 in $5 \% \mathrm{BSA}$ ) at $4{ }^{\circ} \mathrm{C}$ overnight, followed by Alexa fluor 488 second antibody $(1: 150$ in $5 \% \mathrm{BSA}$ ) for $1 \mathrm{~h}$ and DAPI for $5 \mathrm{~min}$. Slides were scanned and photographed using an Olympus BX51 Microscope (Olympus, Tokyo, Japan).

\section{Colony formation assay}

Cells were seeded in a six-well plate at a density of 1000 cells/well and were grown for 2 weeks. The cell colonies that emerged were washed with phosphate-buffered saline, fixed with $4 \%$ formalin for $10 \mathrm{~min}$, and stained with crystal violet $(0.01 \%$ in ethanol, Sigma) for $20 \mathrm{~min}$. The number of colonies from each well was counted under an inverted microscope.

\section{Tumor xenograft model}

Female athymic nude mice at the age of 4-5 weeks were used according to the protocol, which was in accordance with the guidelines of the Institutional Animal Care and Use Committee of Xi'an Jiaotong University. In all, $200 \mu \mathrm{l}$ serum-free DMEM medium that contained Matrigel (2:1, v/v) with $5 \times 10^{6} \mathrm{JEG}-3$ sublines (vector or shSFRP2-1 and SFRP2-2) were subcutaneously injected into both flanks. The mice were sacrificed, xenografts were harvested at day 14 , and tumors were weighed and measured. A small part of the individual xenograft was fixed with $4 \%$ paraformaldehyde, embedded in paraffin and subsequently stained by immunohistochemistry. The remaining xenografts were rapidly placed in liquid nitrogen and used for western blotting and qRT-PCR.

\section{Clinical specimens and immunohistochemistry}

Paraffin sections of the first trimester villus (FTV), HM, invasive mole (IM) and CC were obtained from the Department of pathology, the First Affiliated Hospital of Xi'an Jiaotong University, Xi'an, China. The specimens were histologically diagnosed at this hospital from 2013 to 2017. For the use of these clinical materials for research purposes, prior patient consents and approval from the Institutional Research Ethics Committee of the First Affiliated Hospital of Xi'an Jiaotong University were obtained. The immunohistochemistry was performed using the EnVision $^{\mathrm{TM}}$ system (Dako, Carpinteria, CA, USA). Tissue sections were de-paraffinized, rehydrated and subjected to 5-min pressure cooker antigen retrieval 


\section{Cellular Physiology Cell Physiol Biochem 2018;50:1815-1831 \begin{tabular}{l|l|l} 
and Biochemistry Published online: 3 November 2018 & $\begin{array}{l}\text { ○ } 2018 \text { The Author(s). Published by S. Karger AG, Basel } \\
\text { www.karger.com/cpb }\end{array}$ \\
\hline
\end{tabular}}

Zeng et al.: Secreted Frizzled Related Protein 2 Modulates Epithelial-Mesenchymal

Transition and Stemness

methods, 10-min of endogenous enzyme block, incubation with the primary antibody overnight at $4{ }^{\circ} \mathrm{C}$, and 30-min Dako Cytomation EnVision-HRP reagent incubation for primary antibodies. The signals were subsequently detected by diaminobenzidine, followed by hematoxylin counterstaining. Staining signals were photographed using an Olympus BX51 microscope (Olympus). The results were evaluated according to the intensity of the staining ( 0 , none; 1 , weak; 2 , intermediate; 3 , strong) and the percentage of positive cells $(0,0-5 \% ; 1,6-25 \% ; 2,26-50 \% ; 3,51-75 \% ; 4,76-100 \%)$. Thus, the former multiplied the latter to obtain the final result: negative ( 0 score), weak (1-4 score), moderate (5-8 score) and strong ( $9-12$ score).

\section{Statistical analysis}

All experiments were repeated at least three times. All statistical analyses were performed using GraphPad Prism version 5.0 software (GraphPad Software, La Jolla, CA, USA). All data were presented as the mean \pm S.E.M., and the differences were compared via the two-tailed Student's t-test between two groups or one-way ANOVA with a Bonferroni correction among several groups. ${ }^{*} \mathrm{P}<0.05,{ }^{* *} \mathrm{P}<0.01,{ }^{* * *} \mathrm{P}<0.001$.

\section{Results}

\section{SFRP2 is downregulated in human CC tissues and CC cell lines}

To investigate the expression pattern of SFRP2 in CC tissues, we performed immunohistochemical staining in 7 cases of CC, 9 cases of IM, 16 cases of HM and 16 cases of FTV. As shown in Fig. 1A, B and C, we determined that the expression of SFRP2 protein was lower in the CC and IM tissues than the HM tissues and FTV $(\mathrm{P}<0.001)$, whereas there was no difference between CC and IM or HM and FTV. Moreover, we analyzed the expression of

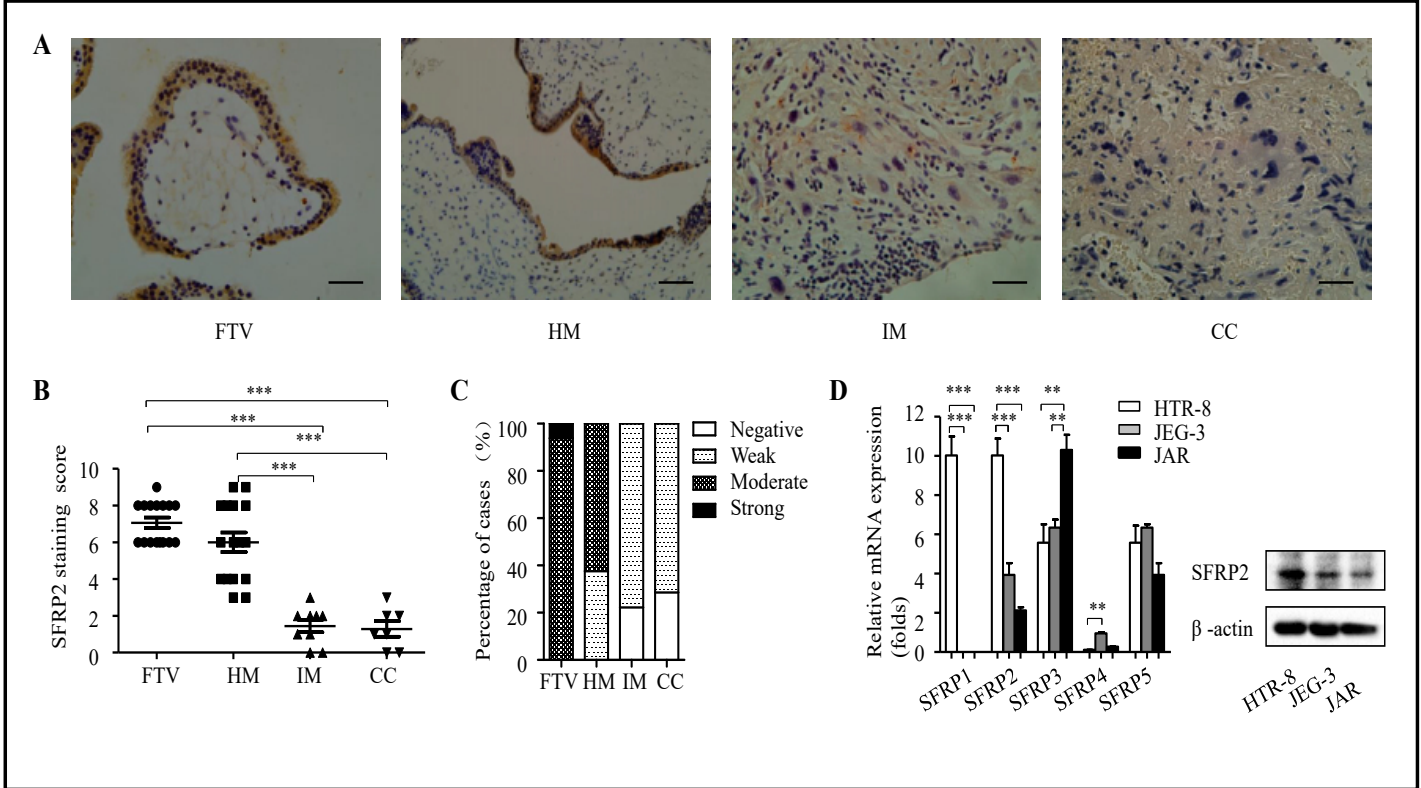

Fig. 1. Decreased SFRP2 expression was detected in CC tissues and CC cell lines. A. Representative scopes of IHC staining of SFRP2 in FTV, HM, IM and CC. Original magnification, $\times 400$. The scale bar represents $25 \mu \mathrm{m}$. B. Quantification analysis of SFRP2 staining score in CC tissues. Each data point represents an individual patient; First trimester villi (FTV, $n=16)$, hydatidiform mole (HM, n=16), invasive mole (IM, $n=9)$, choriocarcinoma (CC, $n=7$ ). C. Percentage analysis of SFRP2 staining score in CC tissues. Patients were assigned to four categories per IHC staining intensity. 0, no expression; 1-4, faint expression; 5-8, moderate expression; and 9-12, strong expression. D. Expression of SFRP1-5 in HTR-8, JEG-3 and JAR cells by qRT-PCR and expression of SFRP2 by western blotting using cell lysates with $\beta$-actin as a control. The fold change in mRNA was calculated through relative quantification $\left(2^{-\Delta \Delta C t}\right)$, and GAPDH was used as a loading control. One representative example of three independent experiments is shown. ${ }^{* *} \mathrm{P}<0.01,{ }^{* * *} \mathrm{P}<0.001$. 


\section{Cellular Physiology Cell Physiol Biochem 2018;50:1815-1831 and Biochemistry \begin{tabular}{l|l|l|l} 
DOI: $10.1159 / 000494862$ & 2018 The Author(s). Published by S. Karger AG, Basel \\
\hline
\end{tabular}

Zeng et al.: Secreted Frizzled Related Protein 2 Modulates Epithelial-Mesenchymal

Transition and Stemness

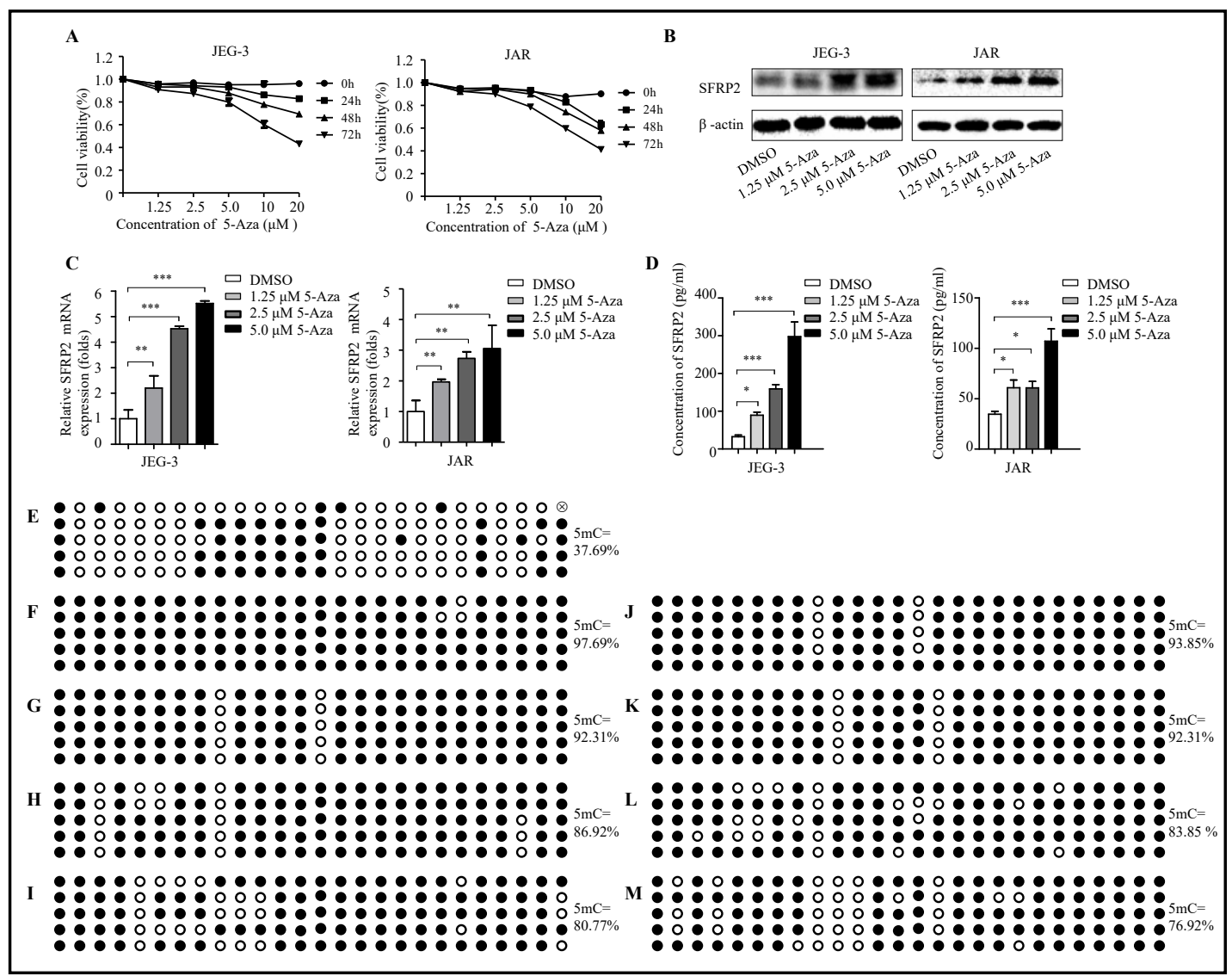

Fig. 2. Expression of SFRP2 could be restored by 5-Aza. A. Cell viability was determined by MTT in JEG3 and JAR cells treated with $0,1.25,2.5,5.0,10.0$, and $20.0 \mu \mathrm{M} \mathrm{5-Aza} \mathrm{for} 72 \mathrm{~h}$. B. Expression profiling of SFRP2 at the concentrations of $0,1.25,2.5$, and $5 \mu \mathrm{M}$ after $48 \mathrm{~h}$ treatment in JEG-3 and JAR cells at the protein level was analyzed by western blotting using cell lysates. $\beta$-actin was used as a control. 5-Aza, $5^{\prime}$-Aza2'-deoxycytidine. C. The expression of SFRP2 after treatment with 1.25, 2.5, and $5.0 \mu \mathrm{M} \mathrm{5-Aza} \mathrm{for} 48 \mathrm{~h}$ was tested by qRT-PCR. The fold change in mRNA was calculated through relative quantification $\left(2^{-\Delta \Delta C t}\right)$, and GAPDH was used as a loading control. ${ }^{* *} \mathrm{P}<0.01,{ }^{* * *} \mathrm{P}<0.001$ versus $0 \mu \mathrm{M} 5$-Aza. D. ELISA test of the concentration of SFRP2 in supernatant of JEG-3 and JAR cells incubated with 5-Aza at 0, 1.25, 2.5, and $5 \mu \mathrm{M}$. ${ }^{*} \mathrm{P}<0.05,{ }^{* * *} \mathrm{P}<0.001$ versus DMSO. $\mathrm{E} \sim \mathrm{M}$. Individual results for methylation status at each CpG site, and the BSP showed that SFRP2 promoter methylation in JEG-3 $(\mathrm{F} \sim \mathrm{I})$ and JAR $(\mathrm{J} \sim \mathrm{M})$ cells could be demethylated by 5 -Aza at $0,1.25,2.5$, and $5 \mu \mathrm{M}$; the methylation frequency of SFRP2 promoter in HTR-8 is also shown (E). Each row represents a single DNA clone. Each circle represents a single $\mathrm{CpG}$ site. Filled and open circles indicate methylated and unmethylated cytosines, respectively. $\mathrm{CpG}$, cytosine-phosphate-guanine. $5 \mathrm{mC}$, cytosine-5' methylation.

SFRP2 in the HTR-8 and CC cell lines (JEG-3 and JAR). Consistently, the result showed that SFRP2 was decreased in the JEG-3 and JAR cells compared to HTR-8 at both the mRNA and protein levels (Fig. 1D). Many studies regarding other cancers have reported that SFRP2 was downregulated through CpG hypermethylation of the gene promoter. Thus, we wondered whether the low expression of SFRP2 in CC was related to hypermethylation. To clarify this issue, we assessed the methylation level of the SFRP2 gene promoter. We only conducted BSP in HTR-8, JEG-3 and JAR cells because it was extremely difficult to obtain fresh CC tissues; we showed that the SFRP2 promoter methylation frequency was significantly increased in the JEG-3 and JAR cells compared to the HTR-8 cells (Fig. 2E, F and J). Overall, the data suggested that there was a correlation between SFRP2 promoter methylation and decreased SFRP2 expression in both JEG-3 and JAR cells, thus implying that decreased SFRP2 may be associated with the tumorigenesis and progression of CC. 


\section{Cellular Physiology Cell Physiol Biochem 2018;50:1815-1831 \\ \begin{tabular}{l|l|l} 
and Biochemistry Published online: 3 November 2018 & $\begin{array}{l}\text { (c) } 2018 \text { The Author(s). Published by S. Karger AG, Basel } \\
\text { www.karger.com/cpb }\end{array}$ \\
\hline
\end{tabular} \\ Zeng et al.: Secreted Frizzled Related Protein 2 Modulates Epithelial-Mesenchymal}

Transition and Stemness

\section{Restoration of SFRP2 expression is induced by 5-Aza in CC cell lines}

First, the BSP test showed that the methylation level was higher in the JEG-3 and JAR cells than the HTR-8 cells, which implies that there was a potential relationship between the decreased expression and high methylation frequency of SFRP2 in CC. To ascertain this association, we utilized 5-Aza, a methyltransferase inhibitor, to validate the expression profile of SFRP2. An MTT assay was employed to determine the optimal concentration of 5-Aza used to induce demethylation in JEG-3 and JAR cells (Fig. 2A); the results indicated that 5-Aza had a concentration-dependent and time-dependent effect on cell viability in both JEG-3 and JAR cells. With the increasing concentration of treatment with 5-Aza, the protein and mRNA levels of SFRP2 significantly increased as shown in Fig. 2B and Fig. 2C, respectively. The ELISA test simultaneously showed a dose effect of 5-Aza on SFRP2 expression the concentrations of $0,1.25,2.5$, and $5.0 \mu \mathrm{M}$ after $48 \mathrm{~h}$ treatment in JEG-3 and JAR cells (Fig. 2D). Furthermore, the BSP test showed that demethylation of the SFRP2 gene was efficiently induced by 5 -Aza at the concentrations of $0,1.25,2.5$, and $5.0 \mu \mathrm{M}$ for $48 \mathrm{~h}$ in both JEG-3 and JAR cells, as shown by representative BSP images (Fig. 2F-I and Fig. 2J-M). Taken together, demethylation of the SFRP2 gene promoter by 5-Aza for $48 \mathrm{~h}$ restored the SFRP2 expression in JEG-3 and JAR cells. The highest demethylation efficiency among JEG-3 and JAR cells could be obtained after incubation with 5-Aza for $48 \mathrm{~h}$ at the concentration of $5.0 \mu \mathrm{M}$. Thus, we used 5-Aza at the concentration of $5.0 \mu \mathrm{M}$ to treat CC cell lines for $48 \mathrm{~h}$.

\section{Demethylated SFRP2 promoter cripples migratory and invasive abilities in CC cells}

We initially investigated the change of the EMT phenotype in JEG-3 and JAR cells. Western blotting assay showed that the epithelial marker (i.e., E-cadherin) increased, whereas the mesenchymal markers (i.e., N-cadherin, Vimentin, and Twist), MMP2, and MMP9 decreased at the protein level in JEG-3 and JAR cells treated with 5-Aza compared with the DMSO control (Fig. 3A). The Transwell assay subsequently indicated that in contrast to the DMSO control, the migratory and invasive abilities were strikingly inhibited in JEG-3 and JAR cells when treated with 5-Aza at the concentration of $5 \mu \mathrm{M}$ for $48 \mathrm{~h}$ (Fig. 3B). The scratch wound assay simultaneously indicated that the CC cell lines JEG-3 and JAR treated with 5-Aza showed a weaken ability to migrate compared with the untreated cell lines, shown by quantification and representative images in Fig. 3C. Moreover, we explored the stemness transformation in CC cells lines. The expression of Oct4 and Nanog was decreased in JEG-3 and JAR cells after incubation with 5-Aza (Fig. 3D). Moreover, the clone formation number in the JEG-3 and JAR cells treated with 5-Aza was substantially decreased compared with the untreated cells (Fig. 3E). Overall, increased SFRP2 through demethylation by 5-Aza increased the expression of SFRP2 and subsequently crippled the EMT phenotype and stemness, as well as significantly prohibited cell migration and invasion in JEG-3 and JAR cells.

\section{SFRP2 knockdown promotes EMT phenotype and stemness in CC cells}

The efficiency of the SFRP2 knockdown was confirmed by western blotting assay and qRT-PCR (Fig. 4A). First and foremost, the western blotting results indicated that the epithelial marker (i.e., E-cadherin) was decreased, whereas the mesenchymal markers (i.e., N-cadherin and Twist), MMP2, and MMP9 were increased in the SFRP2 knockdown JEG-3 and JAR cells compared with the empty vector control (Fig. 4B). Furthermore, the number of migratory and invasive cells substantially increased in the SFRP2-deficient JEG-3 and JAR cells in contrast to the empty vector control (Fig. 4C). Moreover, the migratory distance was augmented when SFRP2 was knocked down (Fig. 4D). Together, the data implied that SFRP2 knockdown could promote the EMT phenomenon in JEG-3 and JAR cells. Furthermore, we examined the stemness in SFRP2-deficient JEG-3 and JAR cells. The western blotting assay demonstrated that the expression of Oct4 and Nanog was increased (Fig. 5A). Moreover, the number of clone formation was increased in the SFRP2-deficient JEG-3 and JAR cells (Fig. 5B). Thus, these data suggested decreased SFRP2 promoted the migratory and invasive potential of JEG-3 and JAR cells. 


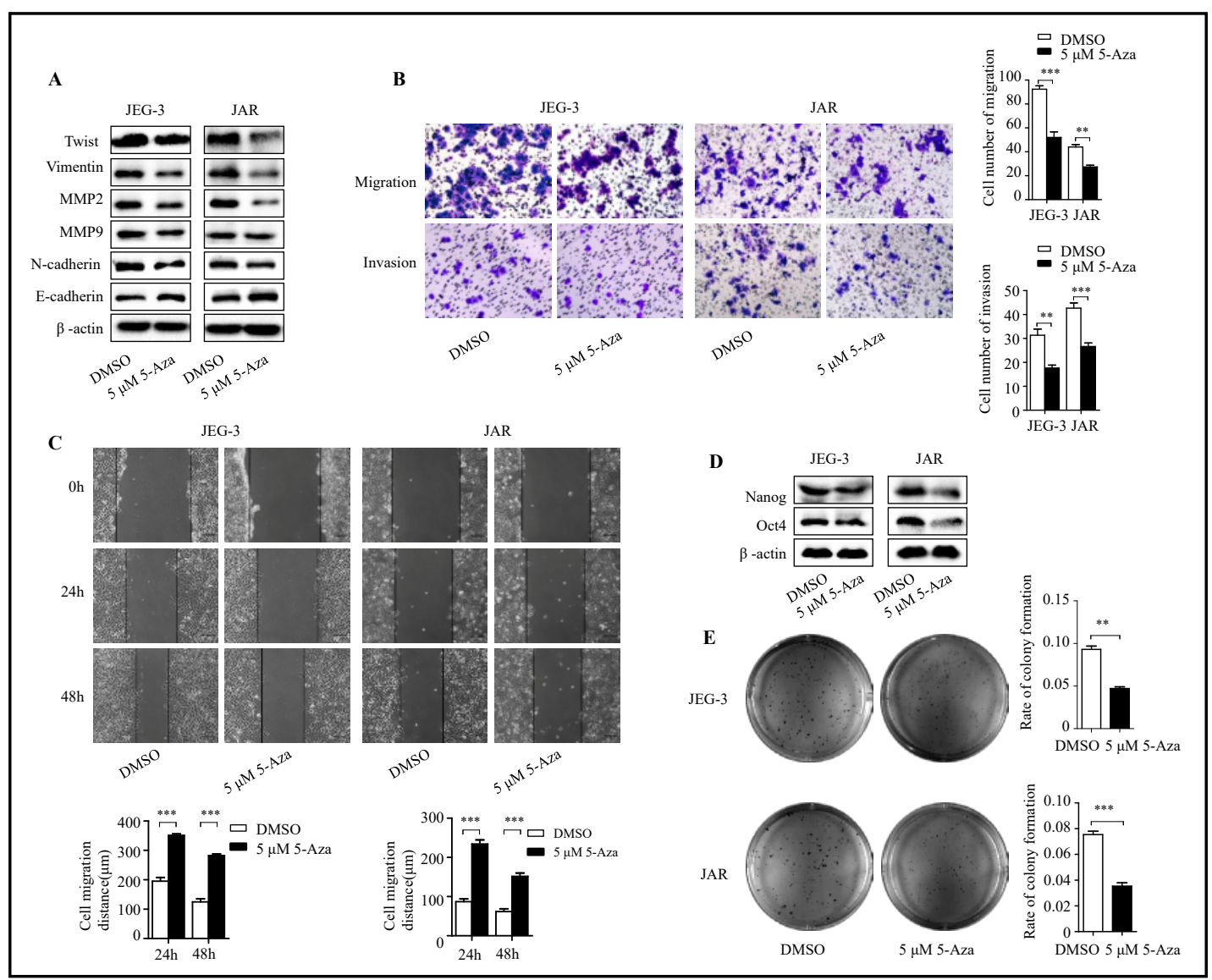

Fig. 3. Demethylated SFRP2 promoter cripples migratory and invasive abilities in CC cells. A. Western blotting assay using cell lysates showed the expression profile of an epithelial marker (i.e., E-cadherin) and mesenchymal markers (i.e., N-cadherin, Vimentin, and Twist), as well as MMP2 and MMP9. $\beta$-actin was used as a control. B. The migratory and invasive abilities were examined by Transwell assay, and representative pictures and the quantification analysis are shown. ${ }^{* *} \mathrm{P}<0.01,{ }^{* * *} \mathrm{P}<0.001$ versus DMSO. C. Representative pictures and quantification analysis of the scratch wound assay. The scale bar represents $100 \mu \mathrm{m} .{ }^{* * *} \mathrm{P}<0.001$ versus DMSO. D. The expression of Oct4 and Nanog was determined by western blotting. $\beta$-actin was used as a control. E. The colony formation assay in JEG-3 and JAR cells treated with 5-Aza versus untreated cells. The colony number was counted and plotted. 5-Aza, 5'-Aza-2'-deoxycytidine. ${ }^{* *} \mathrm{P}<0.01,{ }^{* * *} \mathrm{P}<0.001$ versus DMSO.

\section{SFRP2 regulates EMT phenotype and stemness via Wnt/ $\beta$-catenin pathway in CC cells}

To analyze the effect of the demethylation of the SFRP2 gene promoter on the activation of canonical Wnt signaling, we determined the key components, such as Dvl3, GSK-3 $\beta$, p-GSK-3 $\beta$ (the inactivated form of GSK-3 $\beta$ ) and $\beta$-catenin, at both the protein and mRNA levels (Fig. 6A and Fig. 6B). Western blotting assay determined that Dvl3, $\beta$-catenin and p-GSK-3 $\beta$ were downregulated in JEG-3 and JAR cells when treated with 5-Aza in contrast to the DMSO control, thus illustrating that 5-Aza could suppress canonical Wnt signaling. Moreover, IF showed that 5-Aza conspicuously inhibited nuclear retention of the dominated Wnt signaling factor, $\beta$-catenin, in JEG-3 and JAR cells, which further verifies the canonical Wnt signaling could be inhibited by 5-Aza (Fig. 6C). Furthermore, we added a Wnt activator (BML-284) to JEG-3 and JAR cells treated with 5-Aza and showed that the activity of the Wnt pathway and EMT phenotype and stemness were regained at the protein level (Fig. 6DF). Taken together, the methylation-mediated loss of SFRP2 enhances CC cell migration and invasion via Wnt signaling. Thus, increased SFRP2 through its promoter demethylation with 5-Aza could increase SFRP2 expression, inhibit its nuclear retention and eventually lead to 


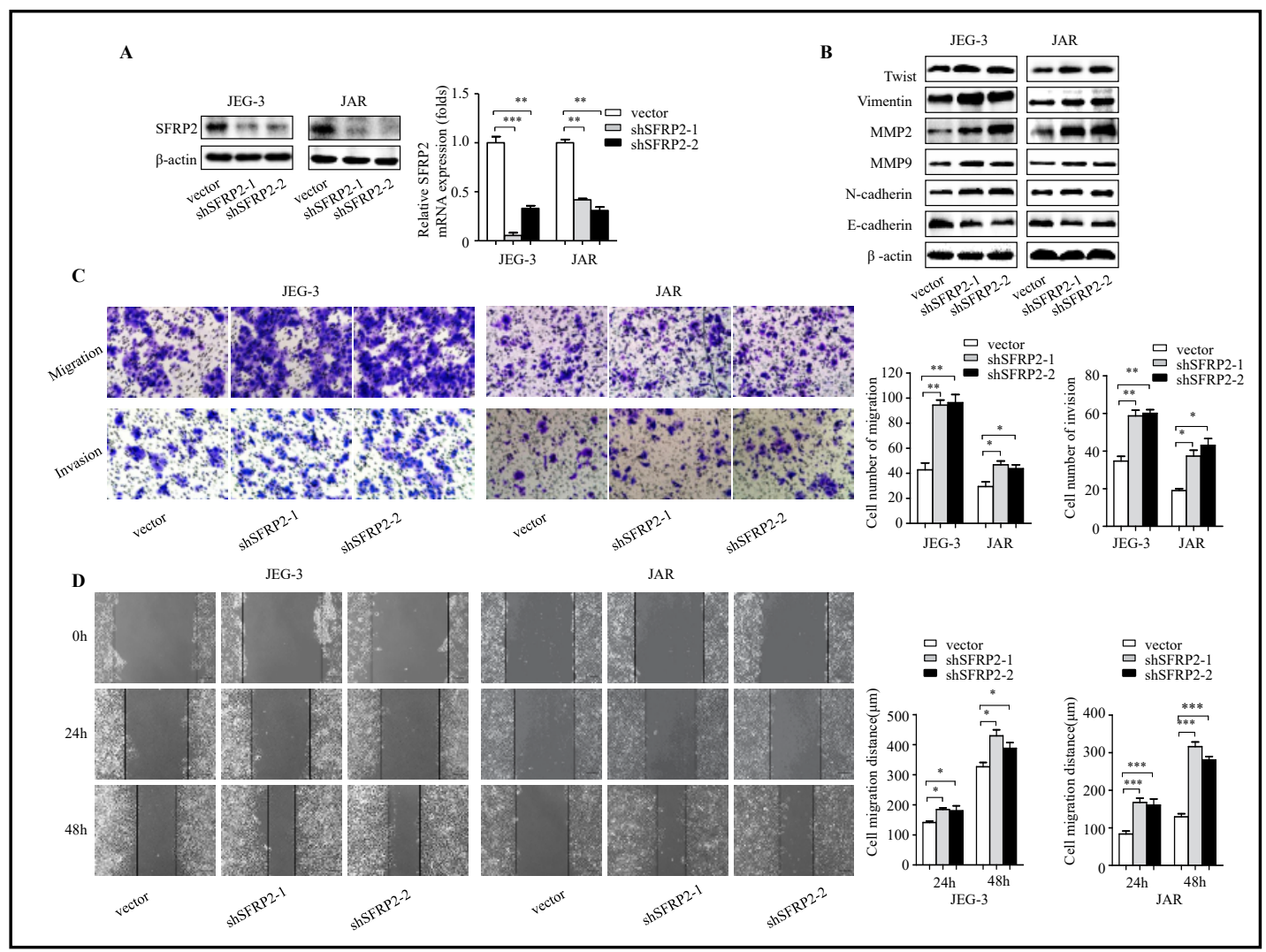

Fig. 4. SFRP2 knockdown promotes EMT phenotype in CC cells. A. The efficiency of SFRP2 knockdown was confirmed by western blotting assay and qRT-PCR in JEG-3 and JAR transfected with SFRP2 shRNAs and vector shRNA. $\beta$-actin was used as a control. ${ }^{* *} \mathrm{P}<0.01,{ }^{* * *} \mathrm{P}<0.001$ versus the empty vector. $\mathrm{B}$. Western blotting assay showed the expression profile of an epithelial marker (i.e., E-cadherin) and mesenchymal markers (i.e., N-cadherin, Vimentin, Twist), as well as MMP2 and MMP9. $\beta$-actin was used as a control. C. The migratory and invasive abilities were examined by the Transwell assay. ${ }^{*} \mathrm{P}<0.05$, ${ }^{* *} \mathrm{P}<0.01$ versus the empty vector. D. The scratch wound assay in JEG-3 and JAR transfected with SFRP2 shRNAs and vector shRNA. ${ }^{*} \mathrm{P}<0.05,{ }^{* * *} \mathrm{P}<0.001$ versus the empty vector.

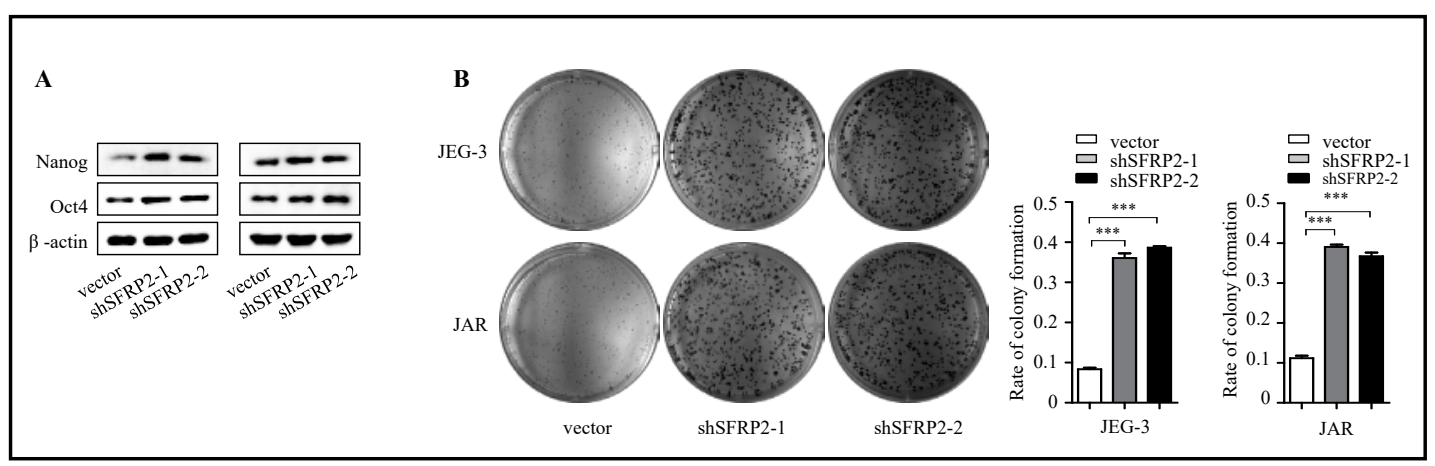

Fig. 5. SFRP2 knockdown promotes stemness in CC cells. A. The expression of Oct 4 and Nanog by western blotting. $\beta$-actin was used as a control. B. The colony formation assay in JEG-3 and JAR cells transfected with SFRP2 shRNAs and vector shRNA. The colony number was counted and plotted. ${ }^{* *} \mathrm{P}<0.01,{ }^{* * *} \mathrm{P}<0.001$ versus the empty vector. 


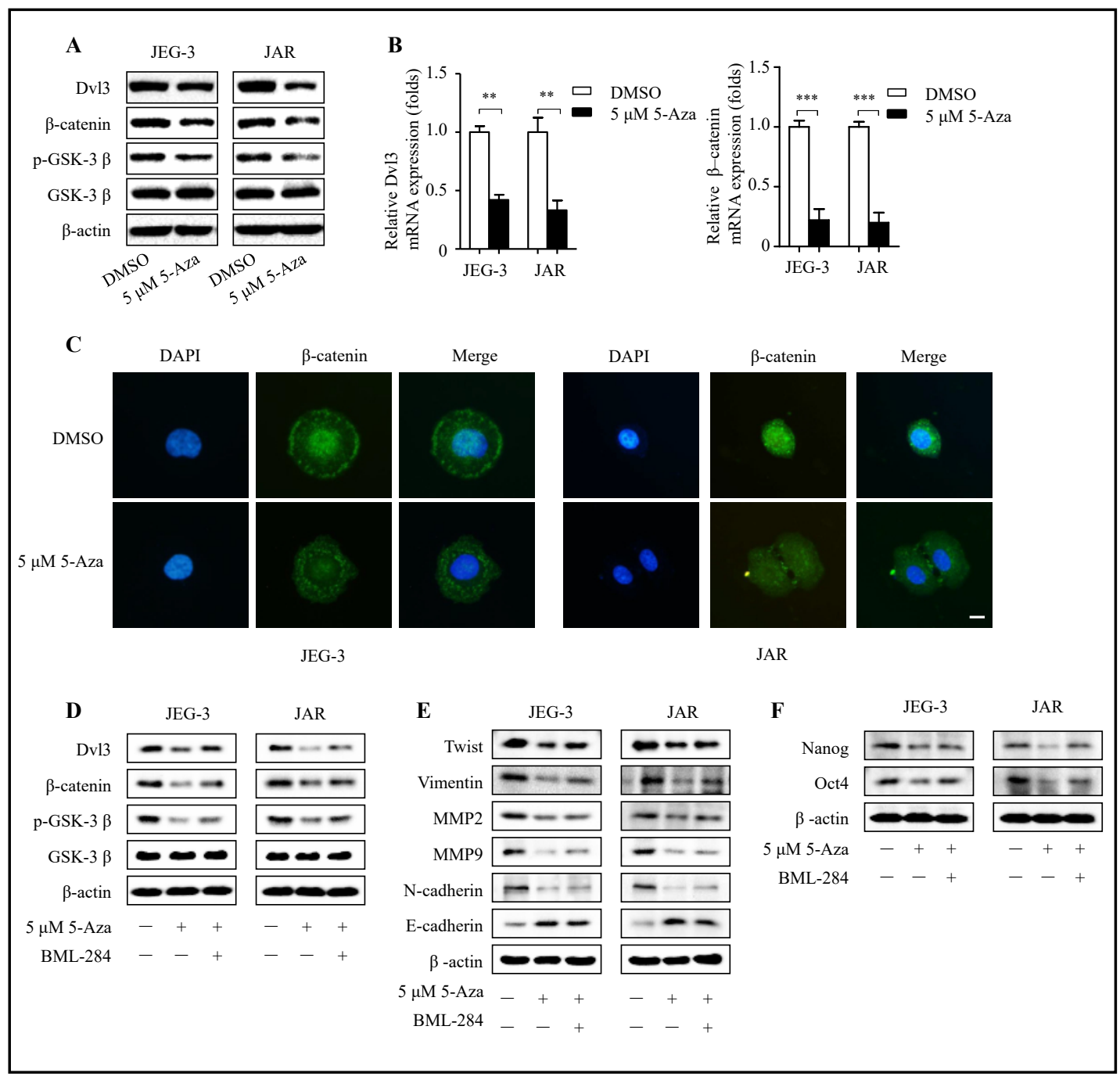

Fig. 6. Demethylation of SFRP 2 promoter suppresses Wnt/ $\beta$-catenin signaling activity. A. Western blotting of Dvl3, $\beta$-catenin, p-GSK-3 $\beta$ and GSK-3 $\beta$ in JEG-3 and JAR cells after treatment with 5-Aza versus DMSO. $\beta$-actin was used as a control. B. Expression of Dvl3 and $\beta$-catenin in JEG-3 and JAR cells treated with $5.0 \mu \mathrm{M} 5$-Aza for $48 \mathrm{~h}$ was tested by qRT-PCR. The fold change in mRNA was calculated through relative quantification $\left(2^{-\Delta \Delta C t}\right.$ ), and GAPDH was used as a loading control. ${ }^{* *} \mathrm{P}<0.01,{ }^{* * *} \mathrm{P}<0.001$ versus DMSO. C. Immunofluorescence (IF) staining with antibodies against $\beta$-catenin (green) and DAPI (nuclei, blue) showed that 5-Aza conspicuously inhibited nuclear retention of $\beta$-catenin in JEG-3 and JAR cells. The scale bar represents $25 \mu \mathrm{m}$. D F. Western blotting analysis of Dvl3, $\beta$-catenin, p-GSK-3 $\beta$, GSK-3 $\beta$ and EMT and stemness markers in JEG-3 and JAR cells after coculture with 5-Aza and the Wnt activator BML-284 versus DMSO. $\beta$-actin was used as a control. 5-Aza, 5'-Aza-2'-deoxycytidine.

inactivation of the Wnt/ $\beta$-catenin pathway, thus resulting in impaired abilities of migration and invasiveness in the CC cell lines JEG-3 and JAR.

We simultaneously determined that Dvl3, $\beta$-catenin and p-GSK- $3 \beta$ were elevated in SFRP2-deficient JEG-3 and JAR cells at both the protein and mRNA levels (Fig. 7A and Fig. 7B). To further elucidate the specific role of canonical Wnt signaling, we treated SFRP2deficient JEG-3 and JAR cells with a specific inhibitor XAV 939 and determined that XAV 939 weakened the activity of Wnt/ $\beta$-catenin signaling (Fig. 7C). In addition, the cells treated with XAV 939 exhibited a decrease of the migratory and invasive capacity (Fig. 8A-B) and the reversal of the EMT phenotype and stemness markers (Fig. 7D and Fig. 8C). SFRP2 knockdown promoted CC cell migration and invasion and stemness through activation of 
Zeng et al:: Secreted Frizzled Related Protein 2 Modulates Epithelial-Mesenchymal

Transition and Stemness

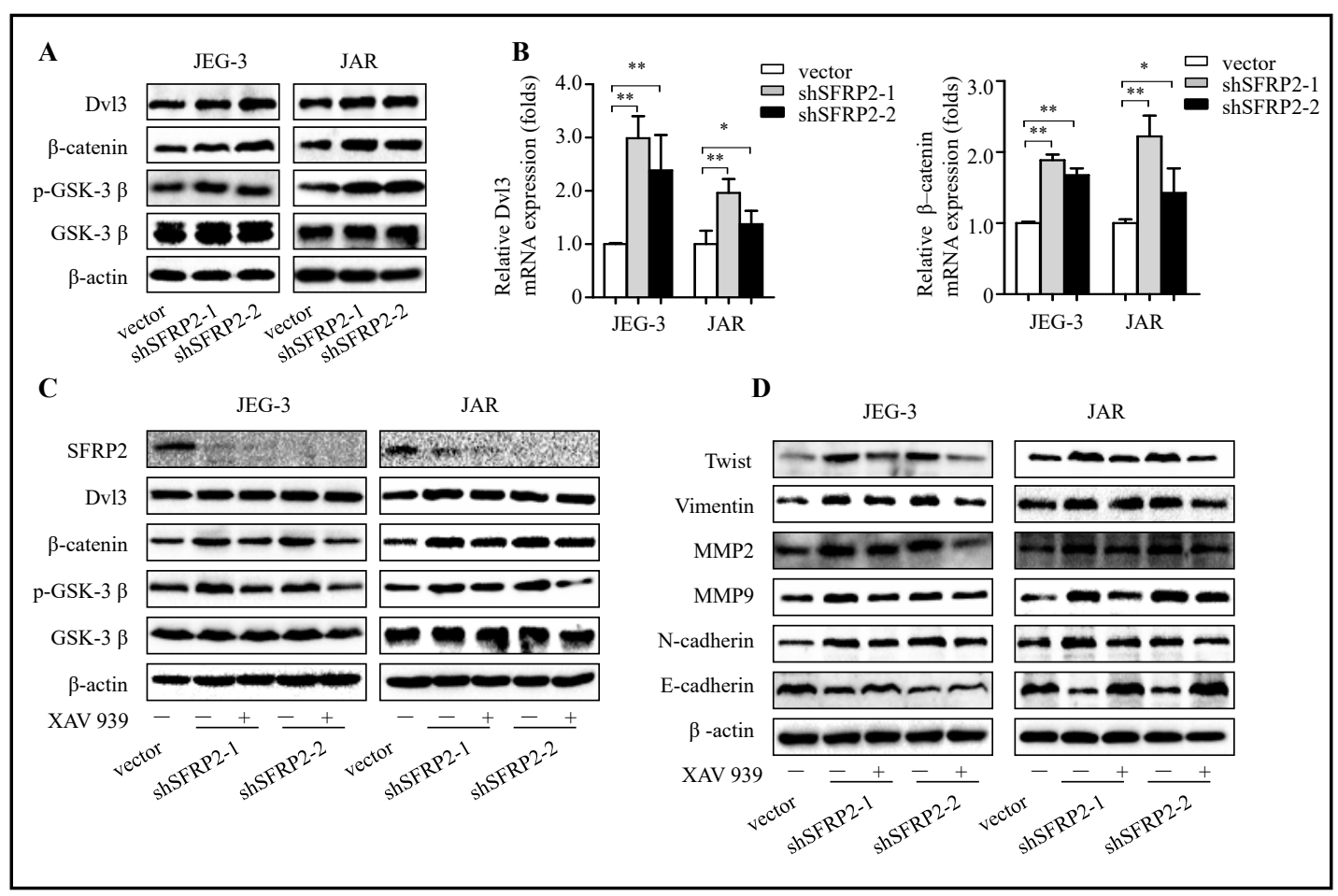

Fig. 7. SFRP2 knockdown activates Wnt/ $\beta$-catenin signaling. A. Western blotting of Dvl3, $\beta$-catenin, p-GSK$3 \beta$ and GSK-3 $\beta$ in JEG-3 and JAR cells transfected with SFRP2 shRNAs and vector shRNA. $\beta$-actin was used as a control. B. Expression of Dvl3 and $\beta$-catenin in JEG-3 and JAR cells transfected with SFRP2 shRNAs and vector shRNA was tested by qRT-PCR. The fold change in mRNA was calculated through relative quantification $\left(2^{-\Delta \Delta C t}\right)$, and GAPDH was used as a loading control. ${ }^{*} \mathrm{P}<0.05,{ }^{*} \mathrm{P}<0.01$ versus empty vector. $\mathrm{C}$ $\sim$ D. Western blotting analysis of Dvl3, $\beta$-catenin, p-GSK-3 $\beta$, GSK-3 $\beta$ and EMT markers in JEG- 3 and JAR cells transfected with SFRP2 shRNAs and vector shRNA after treatment with the Wnt inhibitor XAV 939. $\beta$-actin was used as a control.

the Wnt/ $\beta$-catenin pathway. However, the stimulative effect could be partially blocked by the Wnt/ $\beta$-catenin signaling inhibitor XAV 939. Thus, these data promoted us to propose that decreased SFRP2 expression may function as an invasive promoter via the reduced ability to antagonize canonical Wnt signaling in CC.

\section{SFRP2 knockdown enhances tumor invasive potential in vivo}

Therefore, to further confirm the connection between SFRP2 and CC invasion identified in vivo, we established the subcutaneous xenograft using JEG-3 expressing empty vector control non-targeting shRNA or SFRP2 shRNA. This study found that the expression of SFRP2 was low in CC tissues. To simulate the natural biological behavior in human body, we only examined the function of downregulated SFRP2 in vivo. We identified an increased tumor size and weight in the SFRP2 shRNA-transfected groups compared with the vector shRNAtransfected group (Fig. 9A). Moreover, we examined the expression of SFRP2, $\beta$-catenin and MMP2 by IHC in the harvested xenografts; in line with the in vitro findings, JEG-3/shSFRP2 tumors exhibited lower SFRP2 expression with a strong $\beta$-catenin and MMP2 expression staining compared to the JEG-3/vector (Fig. 9B). Furthermore, western blotting and qRT-PCR of the SFRP2, $\beta$-catenin, Dvl3 and EMT markers in xenograft tissues also showed the same changing trend identified in vivo (Fig. 9C-D). These results indicated that SFRP2 knockdown promoted the invasiveness in CC in vivo. 


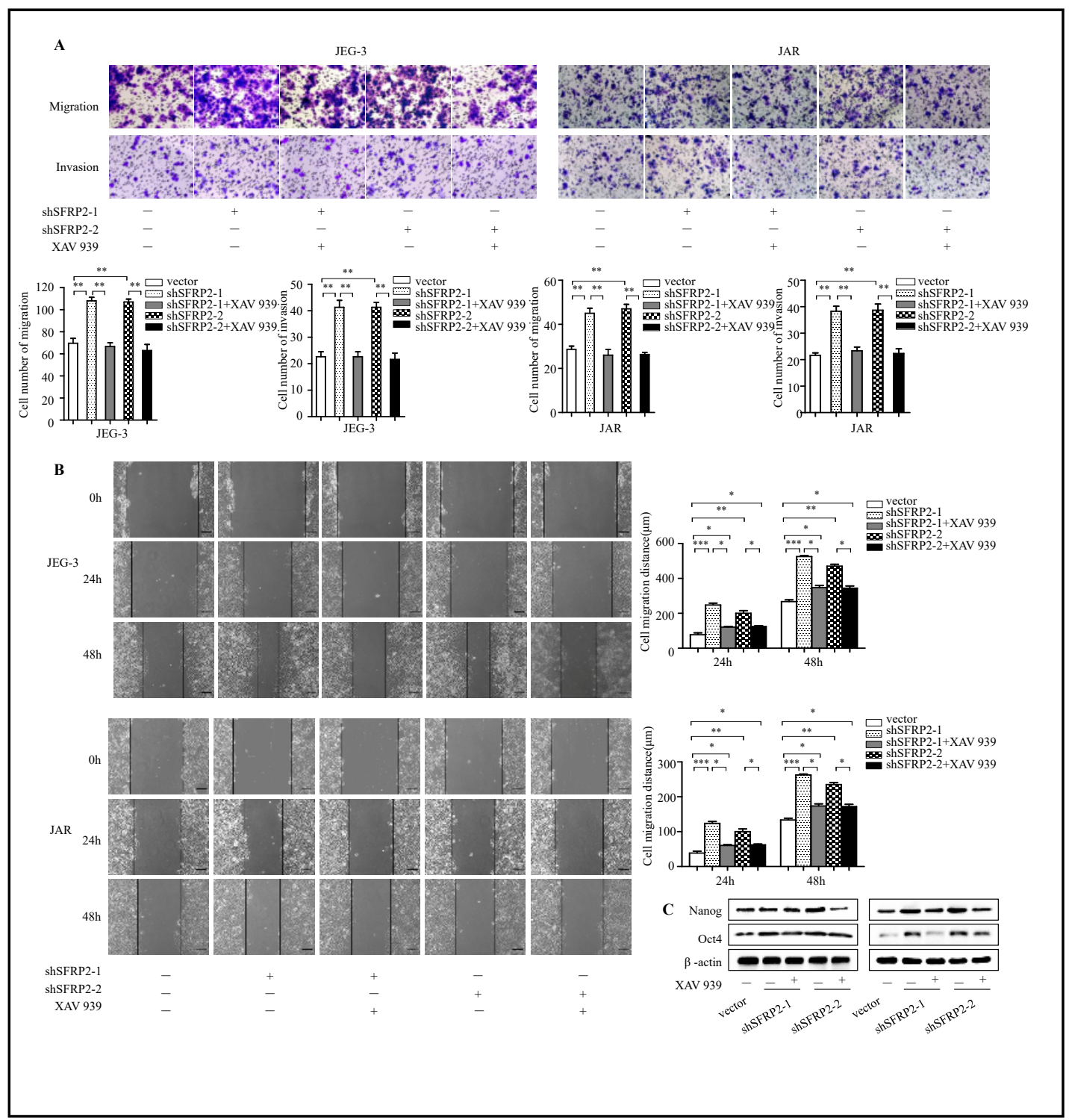

Fig. 8. SFRP2 knockdown promotes EMT and stemness through activating Wnt/ $\beta$-catenin signaling. A. The migratory and invasive capacity was determined by Transwell assay in JEG-3 and JAR cells transfected with SFRP2 shRNAs and vector shRNA after treatment with the Wnt inhibitor XAV 939. Representative images and the quantification analysis are shown. ${ }^{* *} \mathrm{P}<0.01$. B. The scratch wound assay in JEG-3 and JAR cells transfected with SFRP2 shRNAs and vector shRNA after treatment with the Wnt inhibitor XAV 939. Representative images and the quantification analysis are shown. The scale bar represents $100 \mu \mathrm{m}$. ${ }^{*} \mathrm{P}<0.05$, ${ }^{* *} \mathrm{P}<0.01,{ }^{* * *} \mathrm{P}<0.001$. C. Western blotting analysis of Oct 4 and Nanog in JEG-3 and JAR cells transfected with SFRP2 shRNAs and vector shRNA after treatment with the Wnt inhibitor XAV 939. 


\section{Cellular Physiology

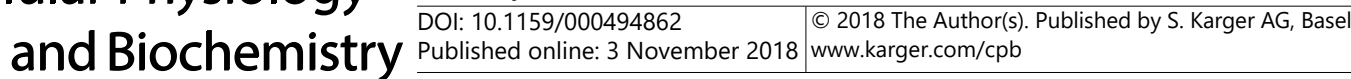

Zeng et al.: Secreted Frizzled Related Protein 2 Modulates Epithelial-Mesenchymal

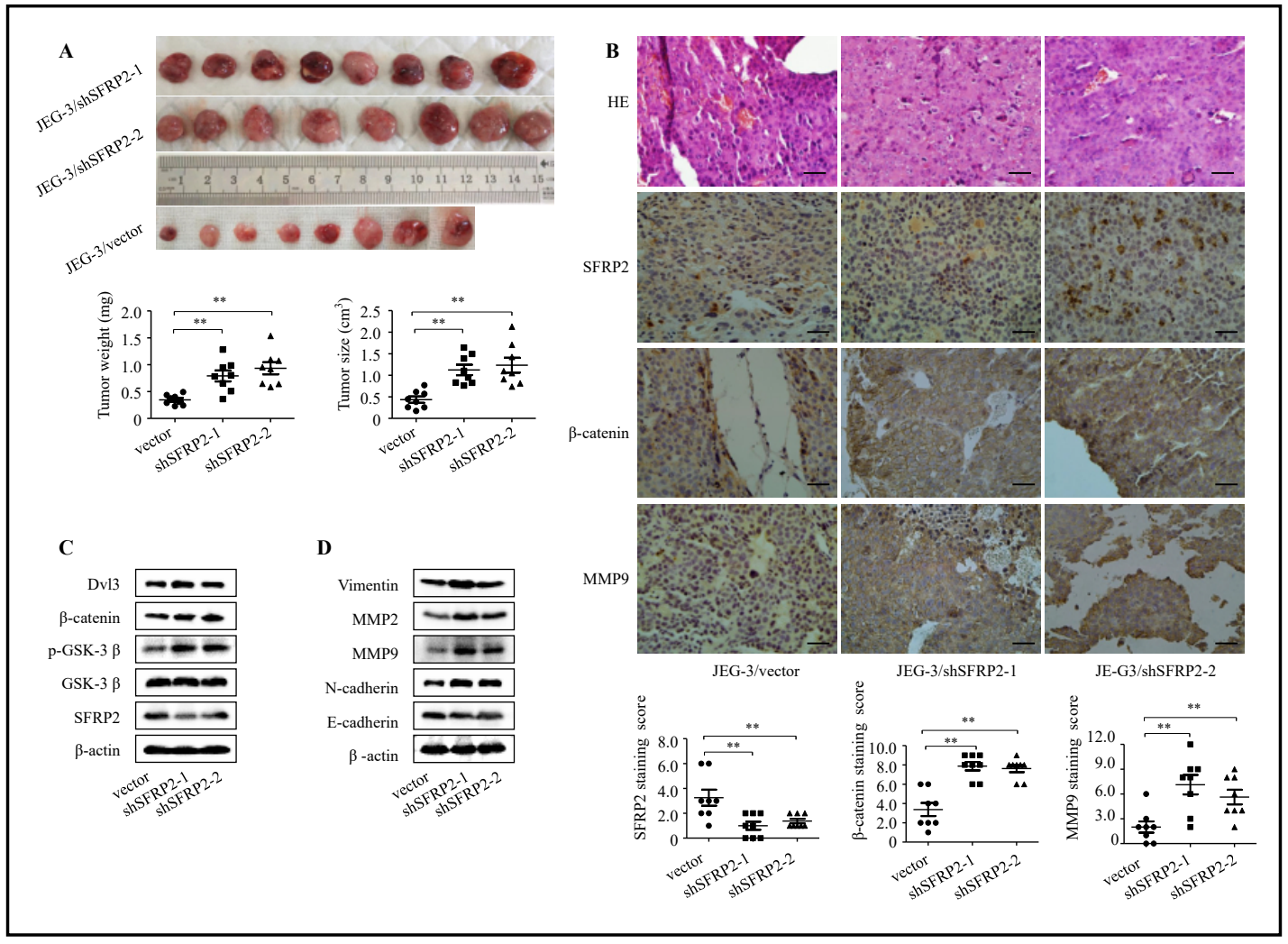

Fig. 9. Decreased SFRP2 enhances tumor invasive potential in vivo. A. Representative images of and quantification analysis of subcutaneous xenografts in nude mice implanted with JEG-3/shSFRP2-1, JEG3/shSFRP2-2 and JEG-3/vector sublines $(\mathrm{n}=8)$. Xenograft weight $(\mathrm{mg})$ and size $(\mathrm{cm})$ were measured. ${ }^{* *} \mathrm{P}<0.01$ versus the JEG-3/vector subline. B. Representative HE and imunohistochemistry staining of SFRP2, $\beta$-catenin and MMP9 in xenograft tissues from xenograft tumors. The scale bar represents $25 \mu \mathrm{m}$. Each data point represents an individual sample. HE, hematoxylin and eosin. ${ }^{* *} \mathrm{P}<0.01$ versus the JEG-3/ vector. C $\sim$ D. Western blotting of SFRP2, Dvl3, $\beta$-catenin, p-GSK-3 $\beta$, GSK-3 $\beta$ and EMT markers in JEG-3/ shSFRP2-1, JEG-3/shSFRP2-2 and JEG-3/vector sublines. $\beta$-actin was used as a control.

\section{Discussion}

Patients with metastatic CC typically require more courses of multi-agent chemotherapy and even potentially brain irradiation, thus posing substantial threats to women's reproductive ability and quality of life $[22,23]$. Worse still, the final outcome remains unsatisfactory even when various treatment modalities are applied. Thus, it is extremely urgent to identify the molecular mechanisms implicated in CC invasion and metastasis and search for the therapeutic target for metastatic CC. We demonstrated that SFRP2 was decreased expressed in CC specimens and CC cell lines, and the low expressed SFRP2 could promote tumor invasion and metastasis in $\mathrm{CC}$ through the Wnt/ $\beta$-catenin pathway both in vivo and in vitro.

Previous studies have supported SFRPs as tumor suppressors because their expression is often silenced in cancers by promoter hypermethylation. In recent years, numerous reports have reported SFRP2, a Wnt inhibitor, was downregulated through CpG island methylation at its gene promoter in various human cancers, including gastric carcinoma [24], hepatocellular carcinoma [25, 26], melanoma [27] and colorectal cancers [28]. However, whether the methylation of SFRP2, a member of SFRPs, may be involved in the pathogenesis of CC has not been well elucidated. In the present study, we showed that SFRP2 expression was decreased, whereas the methylation status was increased in CC cell lines and 5-Aza could restore the expression of SFRP2 through demethylation in JEG-3 and JAR cells. Thus, we hypothesized 


\section{Cellular Physiology Cell Physiol Biochem 2018;50:1815-1831 \begin{tabular}{l|l|l} 
and Biochemistry Published online: 3 November 2018 & $\begin{array}{l}\text { (c) } 2018 \text { The Author(s). Published by S. Karger AG, Basel } \\
\text { www.karger.com/cpb }\end{array}$
\end{tabular} \\ Zeng et al:: Secreted Frizzled Related Protein 2 Modulates Epithelial-Mesenchymal \\ Transition and Stemness}

that SFRP2 may act as a tumor suppressor in the invasiveness and metastasis of CC.

Next, to validate the role played by SFRP2 in CC, we examined the EMT phenotype and stemness, which were critical for the invasiveness and metastasis, in JEG-3 and JAR cells; the results indicated that increased SFRP2 through promoter demethylation by 5-Aza could restrain the migration and invasion ability, whereas SFRP2 knockdown could promote the migratory and invasive potential of JEG-3 and JAR cells. In addition, the effect of SFRP2 in stemness showed an identical trend. Most importantly, these phenomena were confirmed by similar results in vitro. Thus, it is conceivable that SFRP2 gene silencing through promoter hypermethylation contributes to the high potential of invasiveness and metastasis.

Moreover, studies have suggested that SFRP2 could inhibit the Wnt/ $\beta$-catenin pathway, thus acting as a tumor suppressor $[29,30]$. In contrast, several reports have claimed that SFRP2 induced tumor growth in certain malignancies, including glioma and renal cancer, by activating canonical Wnt signaling or stimulating angiogenesis via a calcineurin/NFAT as non-canonical Wnt transduction in breast cancer [31]. However, whether SFRP2 would function through the $\mathrm{Wnt} / \beta$-catenin pathway in $\mathrm{CC}$ was ill-defined, and the previous findings prompted us to speculate the role of the $\mathrm{Wnt} / \beta$-catenin pathway during this biological behavior. In the absence of Wnt signaling, GSK-3 $\beta$ phosphorylates cytoplasmic $\beta$-catenin, which makes it a target for degradation by the proteasome. However, during aberrant Wnt pathway signaling activation, GSK-3 $\beta$ is inactivated, which results in increased levels of unphosphorylated cytoplasmic $\beta$-catenin. This accumulation of cytoplasmic $\beta$-catenin increases its translocation to the nucleus where it activates various target genes involved in tumor development and progression. Thus, to determine the activity of the Wnt/ $\beta$ catenin pathway in JEG-3 and JAR cells after treatment with 5-Aza, we utilized western blotting and qRT-PCR to examine the expression of dominant components of canonical Wnt signaling, including Dvl3, $\beta$-catenin, and p-GSK-3 $\beta$; the results indicated their expressions were decreased at both the protein and mRNA levels. To further explore the Wnt/ $\beta$-catenin signaling activity, IF was applied to evaluate the distribution of $\beta$-catenin and showed that in contrast to the untreated cells, $\beta$-catenin was mainly located in the plasma in JEG-3 and JAR cells after treatment with 5-Aza. Consistent with this finding, Sun et al. reported that $\beta$-catenin was stabilized in the cytoplasm on Wnt16b-mediated activation of the canonical pathway [32]. Furthermore, a Wnt activator, BML-284, could partially rescue this effect. The activity of the Wnt/ $\beta$-catenin pathway in SFRP2-silencing JEG-3 and JAR cells was also assessed. The results demonstrated that the expressions of Dvl3, $\beta$-catenin, and p-GSK-3 $\beta$ were increased at both the protein and mRNA levels, which indicates that SFRP2 knockdown activated Wnt/ $\beta$-catenin signaling. Furthermore, a Wnt inhibitor, XAV 939, partially weakened this promotive effect. Moreover, XAV 939 abrogated the stimulating effect in the EMT phenotype and stemness caused by SFRP2 knockdown among SFRP2-silencing JEG-3 and JAR cells, which was verified by western blotting of EMT markers and the Transwell assay.

\section{Conclusion}

The current study demonstrated that SFRP2 was downregulated in CC and low expressed SFRP2 could promote migration, invasion, the EMT phenotype and stemness of CC cells via Wnt/ $\beta$-catenin signaling, which will provide the foundation for additional molecular studies, as well as avenues for novel diagnosis and therapeutic interventions.

\section{Acknowledgements}

This study was supported by the National Natural Science Foundation of China (No. 81671491 and No. 81172489). 


\section{Cellular Physiology Cell Physiol Biochem 2018;50:1815-1831 \begin{tabular}{l|l|l|l}
\hline DOI: 10.1159/000494862 & (c) 2018 The Author(s). Published by S. Karger AG, Basel
\end{tabular} and Biochemistry

Zeng et al.: Secreted Frizzled Related Protein 2 Modulates Epithelial-Mesenchymal

Transition and Stemness

\section{Disclosure Statement}

The authors have no conflicts of interest to declare.

\section{References}

1 Hoffner L, Surti U: The genetics of gestational trophoblastic disease: a rare complication of pregnancy. Cancer Genet 2012;205:63-77.

$>2$ Mello JB, Ramos Cirilo PD, Michelin OC, Custodio Domingues MA, Cunha Rudge MV, Rogatto SR, Maesta I: Genomic profile in gestational and non-gestational choriocarcinomas. Placenta 2017;50:8-15.

- 3 Ngan HY, Seckl MJ, Berkowitz RS, Xiang Y, Golfier F, Sekharan PK, Lurain JR: Update on the diagnosis and management of gestational trophoblastic disease. Int J Gynaecol Obstet 2015;131 Suppl 2:S123-126.

4 Brown J, Naumann RW, Seckl MJ, Schink J: 15years of progress in gestational trophoblastic disease: Scoring, standardization, and salvage. Gynecol Oncol 2017;144:200-207.

5 Abitbol S, Dahmani R, Coulouarn C, Ragazzon B, Mlecnik B, Senni N, Savall M, Bossard P, Sohier P, Drouet V, Tournier E, Dumont F, Sanson R, Calderaro J, Zucman-Rossi J, Vasseur-Cognet M, Just PA, Terris B, Perret C, Gilgenkrantz H: AXIN deficiency in human and mouse hepatocytes induces hepatocellular carcinoma in the absence of beta-catenin activation. J Hepatol 2018;10.1016/j.jhep.2017.12.018.

-6 Akrami H, Moradi B, Farahani DB, Mehdizadeh K: Ibuprofen reduces cell proliferation through inhibiting Wnt/beta catenin signaling pathway in Gastric Cancer Stem Cells. Cell Biol Int 2018;10.1002/cbin.10959.

7 Yin P, Song G, Jiang Z: Cisplatin suppresses proliferation, migration and invasion of nasopharyngeal carcinoma cells in vitro by repressing the Wnt/beta-catenin/Endothelin-1 axis via activating B cell translocation gene 1. Cancer Chemother Pharmacol 2018;10.1007/s00280-018-3536-5.

-8 Zhou J, Toh SH, Chan ZL, Quah JY, Chooi JY, Tan TZ, Chong PSY, Zeng Q, Chng WJ: A loss-of-function genetic screening reveals synergistic targeting of AKT/mTOR and WTN/beta-catenin pathways for treatment of AML with high PRL-3 phosphatase. J Hematol Oncol 2018;11:36.

-9 Nusse R, Clevers H: Wnt/beta-Catenin Signaling, Disease, and Emerging Therapeutic Modalities. Cell 2017;169:985-999.

10 Kaur A, Webster MR, Marchbank K, Behera R, Ndoye A, Kugel CH, 3rd, Dang VM, Appleton J, O'Connell MP, Cheng P, Valiga AA, Morissette R, McDonnell NB, Ferrucci L, Kossenkov AV, Meeth K, Tang HY, Yin X, Wood $\mathrm{WH}, 3 \mathrm{rd}$, Lehrmann $\mathrm{E}$ et al.: sFRP2 in the aged microenvironment drives melanoma metastasis and therapy resistance. Nature 2016;532:250-254.

11 Lee GA, Hwang KA, Choi KC: Roles of Dietary Phytoestrogens on the Regulation of Epithelial-Mesenchymal Transition in Diverse Cancer Metastasis. Toxins (Basel) 2016;8:pii:E162.

12 Friedl P, Wolf K: Tumour-cell invasion and migration: diversity and escape mechanisms. Nat Rev Cancer 2003;3:362-374.

13 Hanahan D, Weinberg RA: Hallmarks of cancer: the next generation. Cell 2011;144:646-674.

14 Zhang Y, Zhang Y: Forkhead box C2 promotes the invasion ability of human trophoblast cells through Hedgehog (Hh) signaling pathway. Cell Biol Int 2018;10.1002/cbin.10953.

15 Csermely P, Hodsagi J, Korcsmaros T, Modos D, Perez-Lopez AR, Szalay K, Veres DV, Lenti K, Wu LY, Zhang XS: Cancer stem cells display extremely large evolvability: alternating plastic and rigid networks as a potential Mechanism: network models, novel therapeutic target strategies, and the contributions of hypoxia, inflammation and cellular senescence. Semin Cancer Biol 2015;30:42-51.

16 Shigdar S, Li Y, Bhattacharya S, O'Connor M, Pu C, Lin J, Wang T, Xiang D, Kong L, Wei MQ, Zhu Y, Zhou S, Duan W: Inflammation and cancer stem cells. Cancer Lett 2014;345:271-278.

17 Vlashi E, Pajonk F: Cancer stem cells, cancer cell plasticity and radiation therapy. Semin Cancer Biol 2015;31:28-35.

18 Lee E, Yang J, Ku M, Kim NH, Park Y, Park CB, Suh JS, Park ES, Yook JI, Mills GB, Huh YM, Cheong JH: Metabolic stress induces a Wnt-dependent cancer stem cell-like state transition. Cell Death Dis 2015;6:e1805.

19 Yang L, Tang H, Kong Y, Xie X, Chen J, Song C, Liu X, Ye F, Li N, Wang N, Xie X: LGR5 Promotes Breast Cancer Progression and Maintains Stem-Like Cells Through Activation of Wnt/beta-Catenin Signaling. Stem Cells 2015;33:2913-2924. 


\section{Cellular Physiology Cell Physiol Biochem 2018;50:1815-1831

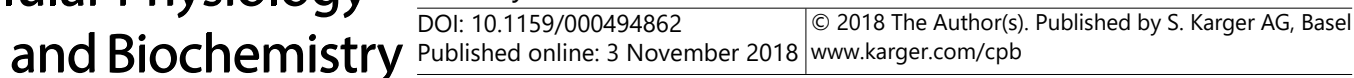

Zeng et al.: Secreted Frizzled Related Protein 2 Modulates Epithelial-Mesenchymal

Transition and Stemness

20 Mao J, Fan S, Ma W, Fan P, Wang B, Zhang J, Wang H, Tang B, Zhang Q, Yu X, Wang L, Song B, Li L: Roles of Wnt/beta-catenin signaling in the gastric cancer stem cells proliferation and salinomycin treatment. Cell Death Dis 2014;5:e1039.

21 Ordonez-Moran P, Dafflon C, Imajo M, Nishida E, Huelsken J: HOXA5 Counteracts Stem Cell Traits by Inhibiting Wnt Signaling in Colorectal Cancer. Cancer Cell 2015;28:815-829.

-22 Essel KG, Bruegl A, Gershenson DM, Ramondetta LM, Naumann RW, Brown J: Salvage chemotherapy for gestational trophoblastic neoplasia: Utility or futility? Gynecol Oncol 2017;146:74-80.

-23 Seckl MJ, Sebire NJ, Berkowitz RS: Gestational trophoblastic disease. Lancet 2010;376:717-729.

24 Yang HJ, Kim SG, Lim JH, Choi JM, Kim WH, Jung HC: Helicobacter pylori-induced modulation of the promoter methylation of Wnt antagonist genes in gastric carcinogenesis. Gastric Cancer 2018;21:237-248.

-25 Shih YL, Hsieh CB, Yan MD, Tsao CM, Hsieh TY, Liu CH, Lin YW: Frequent concomitant epigenetic silencing of SOX1 and secreted frizzled-related proteins (SFRPs) in human hepatocellular carcinoma. J Gastroenterol Hepatol 2013;28:551-559.

-26 Takagi H, Sasaki S, Suzuki H, Toyota M, Maruyama R, Nojima M, Yamamoto H, Omata M, Tokino T, Imai K, Shinomura Y: Frequent epigenetic inactivation of SFRP genes in hepatocellular carcinoma. J Gastroenterol 2008;43:378-389.

27 Luo X, Wei B, Chen A, Zhao H, Huang K, Chen J: Methylation-mediated loss of SFRP2 enhances melanoma cell invasion via Wnt signaling. Am J Transl Res 2016;8:1502-1509.

28 Sui C, Ma J, Chen Q Yang Y: The variation trends of SFRP2 methylation of tissue, feces, and blood detection in colorectal cancer development. Eur J Cancer Prev 2016;25:288-298.

29 Kongkham PN, Northcott PA, Croul SE, Smith CA, Taylor MD, Rutka JT: The SFRP family of WNT inhibitors function as novel tumor suppressor genes epigenetically silenced in medulloblastoma. Oncogene 2010;29:3017-3024.

-30 Saini S, Majid S, Dahiya R: The complex roles of Wnt antagonists in RCC. Nat Rev Urol 2011;8:690-699.

-31 Courtwright A, Siamakpour-Reihani S, Arbiser JL, Banet N, Hilliard E, Fried L, Livasy C, Ketelsen D, Nepal DB, Perou CM, Patterson C, Klauber-Demore N: Secreted frizzle-related protein 2 stimulates angiogenesis via a calcineurin/NFAT signaling pathway. Cancer Res 2009;69:4621-4628.

-32 Sun Y, Campisi J, Higano C, Beer TM, Porter P, Coleman I, True L, Nelson PS: Treatment-induced damage to the tumor microenvironment promotes prostate cancer therapy resistance through WNT16B. Nat Med 2012;18:1359-1368. 